\title{
The large-balloon occupation technique: a new technique for removing multiple biliary stones from a large-diameter bile duct
}
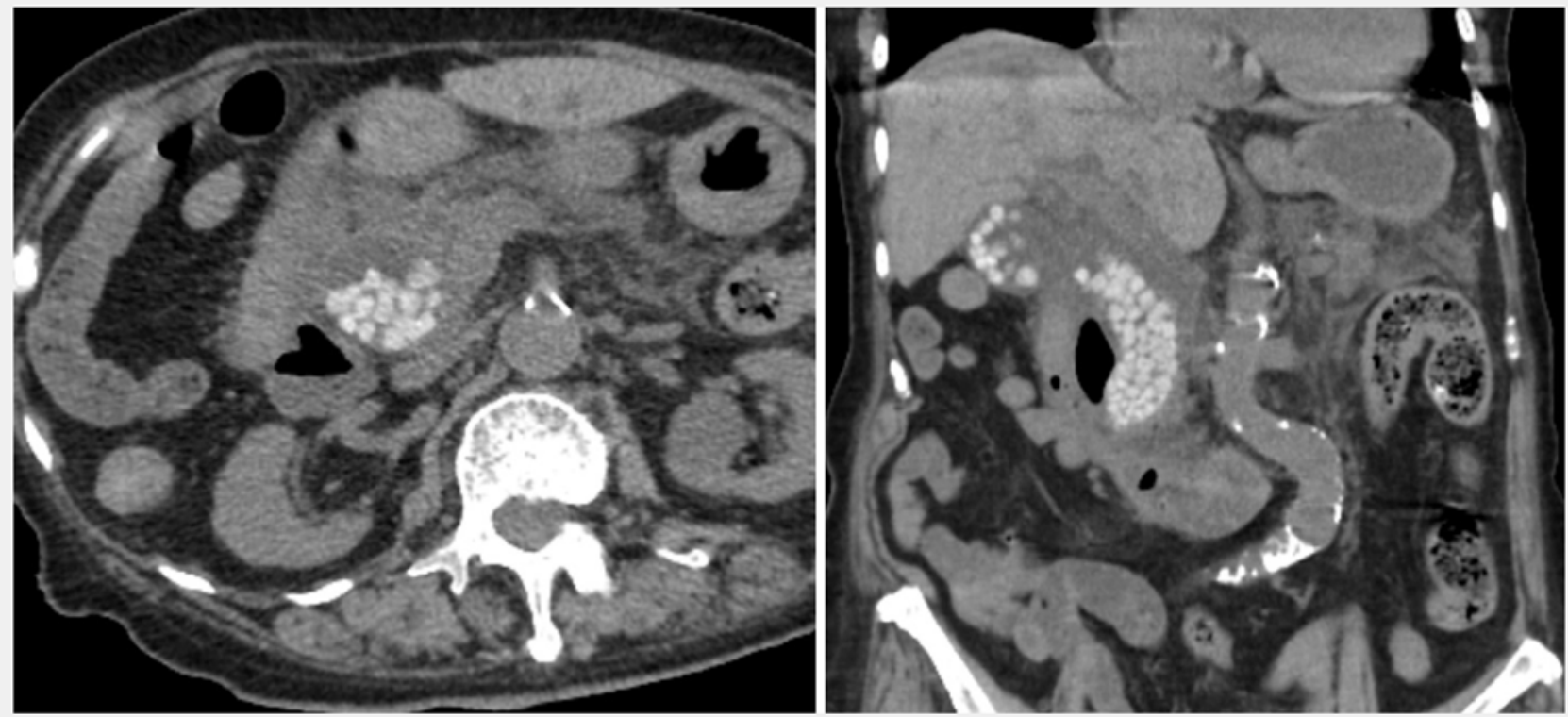

Fig. 1 Plain computed tomography (CT) scan showing many stones in the bile duct and gallbladder: a axial image; b coronal image.
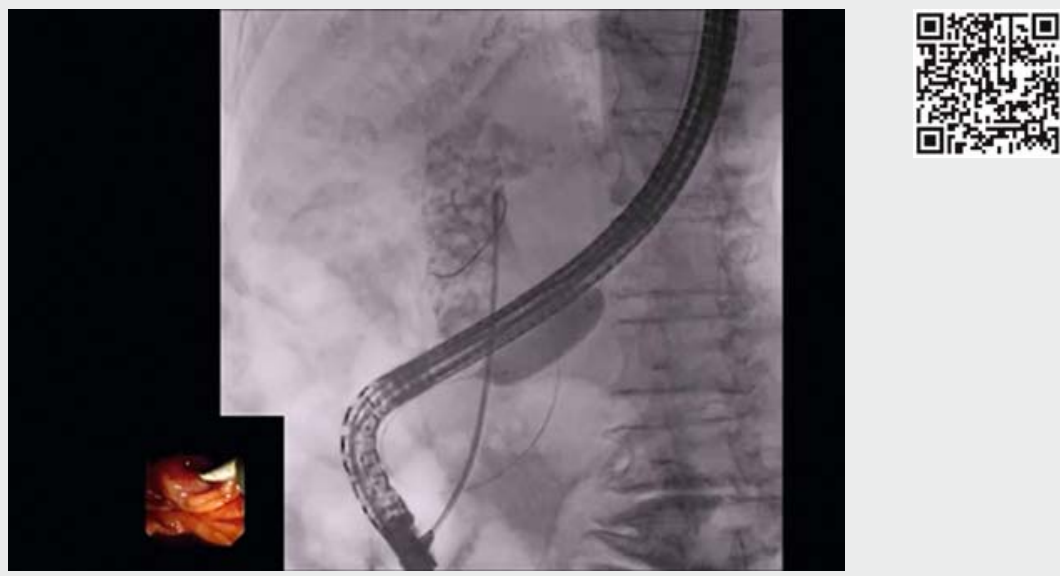

Video 1: The large-balloon occupation technique for endoscopic lithotripsy is demonstrated first in a model then in a 93 -year-old patient. In a markedly dilated bile duct, the space between the stones and the bile duct wall precludes stone removal using an eightwired basket catheter. The steps in the large-balloon occupation technique are as follows:

(1) The large balloon is attached to an endoscope with tape, and the endoscope is inserted.

(2) The guidewire is inserted via the large-balloon catheter, and the wire is grasped endoscopically and inserted into the bile duct. (3) The balloon is inflated, tearing the tape and releasing the balloon from the endoscope. (4) The grasped guidewire is pushed into the bile duct and the guidewire is pulled, thereby inserting the large balloon. (5) The large balloon is inflated in the bile duct to eliminate the space between the stones and the bile duct wall. (6) The stones are grasped with a basket catheter and removed.

Multiple stones, a periampullary diverticulum, and advanced patient age are factors that contribute to difficulty in stone removal [1]. We were able to completely remove the bile duct stones in a 93-year-old woman with a periampullary diverticulum, multiple stones (about 100), and common bile duct of $35 \mathrm{~mm}$ in diameter using the large-balloon occupation technique (LBOT).

The patient visited our hospital because of abdominal pain, and gallstone pancreatitis was diagnosed. Computed tomography (CT) scanning showed about 100 stones in the bile duct ( $\mathbf{F i g} \mathbf{~} \mathbf{1}$ ) and an impacted stone in the papilla. Emergency endoscopic biliary drainage was therefore performed.

After the patient's pancreatitis had improved, endoscopic lithotripsy was performed. Endoscopic retrograde cholangiography (ERC) showed a markedly dilated bile duct $(35 \mathrm{~mm})$ and many filling defects with diameters of $3-12 \mathrm{~mm}$ ( $\triangleright$ Fig.2). At the first session of endoscopic lithotripsy, we were unable to 


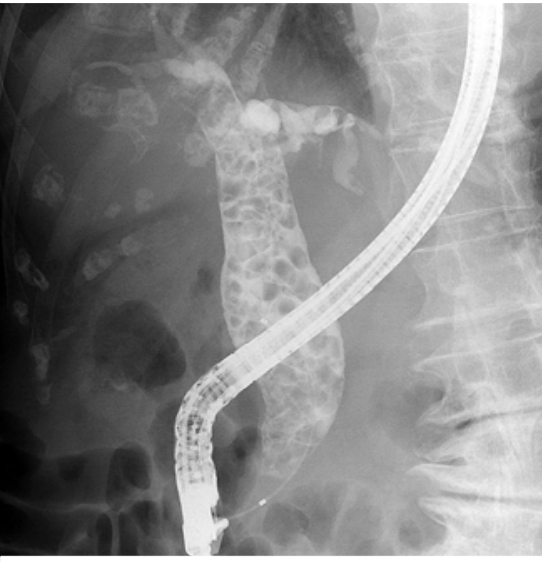

- Fig. 2 Endoscopic retrograde cholangiography (ERC) image showing a markedly dilated bile duct with many filling defects.

\section{ENDOSCOPY E-VIDEOS \\ https://eref.thieme.de/e-videos}

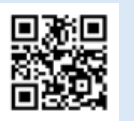

Endoscopy E-Videos is a free access online section, reporting on interesting cases and new techniques in gastroenterological endoscopy. All papers include a high quality video and all contributions are freely accessible online.

This section has its own submission website at

https://mc.manuscriptcentral.com/e-videos grasp the stones because of the considerable space between the stones and bile duct wall. Suctioning of bile and contrast media was used to eliminate this space as much as possible and make it easier to grasp the stones. However, after about 40 stones had been removed, the space between the stones and the bile duct wall gradually increased, again making it difficult to grasp the stones.

A second treatment session was performed 3 days later using the LBOT $(\triangleright$ Video 1 ). This technique allows the stones to be grasped because a large balloon is used to occupy the space between the stones and the bile duct wall ( Fig.3). Stone removal was performed twice using this technique. Repeat ERC and cholangioscopy confirmed that there were no residual stones. Complete stone removal required a total of three procedures (210 minutes). There were no complications.

In patients with a large-diameter bile duct, the relative size of any stones is smaller than that in patients with a small-diameter bile duct, even if the actual stone diameter is the same. This is one of the factors that causes difficulty in stone removal. The LBOT seems to be useful in such patients.

Endoscopy_UCTN_Code_TTT_1AR_2AH
Competing interests

None

The Authors

Hiroshi Yamauchi, Mitsuhiro Kida, Kazuho Uehara, Eiji Miyata, Kosuke Okuwaki, Hiroshi Imaizumi, Wasaburo Koizumi

Department of Gastroenterology, Kitasato

University School of Medicine, Sagamihara city, Kanagawa, Japan

Corresponding author

\section{Hiroshi Yamauchi, MD}

Department of Gastroenterology, Kitasato University School of Medicine, 1-15-1

Kitasato, Minami-ku, Sagamihara, Kanagawa 252-0375, Japan

Fax: $+81-42-7788390$

yhiroshi@kitasato-u.ac.jp

\section{Reference}

[1] Yasuda I, Itoi T. Recent advances in endoscopic management of difficult bile duct stones. Dig Endosc 2013; 25: 376 - 385

\section{Bibliography}

DOI https://doi.org/10.1055/s-0043-106733

Endoscopy 2017; 49: E155-E156

(c) Georg Thieme Verlag KG

Stuttgart · New York

ISSN 0013-726X
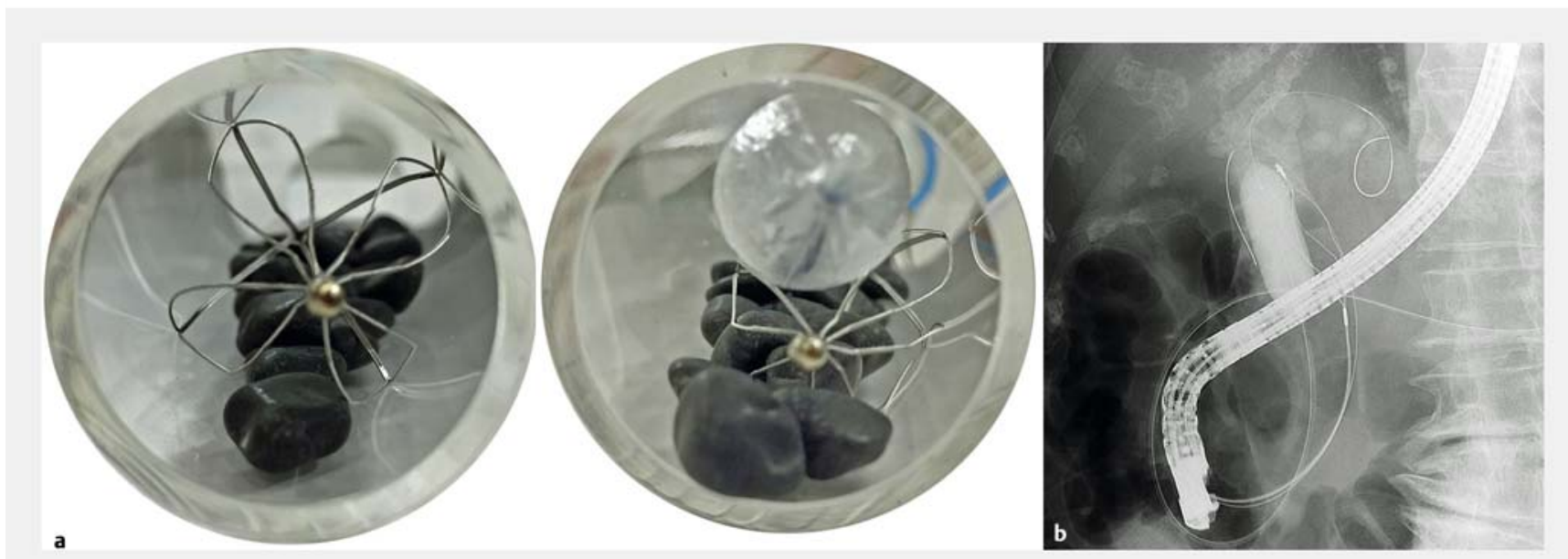

- Fig. 3 a The bile duct model (bile duct diameter $30 \mathrm{~mm}$; stone diameter 5-10 mm). Left: With the use of only an eight-wired basket catheter, the stones could not be grasped because of the considerable space between the bile duct and the stones. Right: When an eight-wired basket catheter and a large balloon were used, the space between the bile duct and stones was eliminated by the large balloon, thereby allowing the stones to be grasped. $\mathbf{b}$ The endoscopic lithotripsy was performed using the large balloon occupation technique. 